\title{
Revista Brasileira de Enfermagem REBEn \\ Ensino de Biossegurança na Graduação em Enfermagem: uma revisão da literatura
}

\author{
The teaching of Biosafety in Nursing Undergraduation: a literature review \\ Enseñanza de Bioseguridad en la Graduación de Enfermería: una revisión de la literatura
}

\section{Andréia de Carvalho Andrade}

Enfermeira, Mestranda em Enfermagem pela Universidade Federal de São Paulo. Membro do Grupo de Estudos e Pesquisa de Administração e Gerenciamento de Serviços de Enfermagem (GEPAG), São Paulo, SP.

Endereco para Contato: Rua Kaneji Kodama, 1651, Condomínio Porto Seguro - casa 26, CEP 08676-010 - Suzano - SP. andreiadecarvalho@terra.com.br

\section{Maria Cristina Sanna}

Enfermeira. Doutora em Enfermagem. Professora Orientadora Credenciada na Universidade Federal de São Paulo. Membro do Grupo de Estudos e Pesquisa de Administração e Gerenciamento de Serviços de Enfermagem (GEPAG), São

Paulo, SP.

\section{RESUMO}

Trata-se de um estudo que realizou um levantamento da produção científica em enfermagem referente ao ensino de biossegurança com o objetivo de investigar o contexto em que se deram e conhecer 0 conteúdo das publicações acerca do ensino de biossegurança na graduação em enfermagem. Foram analisados artigos de periódicos encontrados na consulta às bases de dados LILACS, SciELO, MEDLINE, BDENF, DEDALUS e PERIENF, identificando 26 artigos. Os resultados encontrados proporcionaram a formação e discussão das categorias: "Bases ideológicas e teóricas", "Abordagem histórica de biossegurança", "Riscos ocupacionais e AIDS" e "Educação em biossegurança na formação". Concluise que o número de artigos é pequeno, principalmente artigos enfocando educação em biossegurança, mas houve uma evolução deste conteúdo nos últimos anos.

Descritores: Biossegurança; Ensino; Graduação em enfermagem.

\section{ABSTRACT}

It's a study that made a scientific production survey in nursing regarding to biosafety teaching aiming to investigate its context and discover the content of publishing on biosafety teaching in the nursing undergraduation. It was analyzed the journal articles found consulting LILACS, SCIELO, MEDLINE, BDENF, DEDALUS and PERIENF databases, identifying 26 articles. The results found provided the creation and discussion of these categories: "Ideological and theoretical bases", "Historic approach of biosafety", "Occupational risks and AIDS" and "Biosafety education in graduation". It was concluded that the number of articles is small, mainly the ones focusing on biosafety teaching, but there was an evolution of this content in the last years.

Descriptors: Biosafety; Teaching; Nursing undergraduation.

\section{RESUMEN}

Se trata de un estudio que realizá un levantamiento de la produccion científica en enfermería referente o la enseñanza de bioseguridad con el objetivo de investigar el contexto en que se dieron y conocer el contenido de las publicacions acerca de la ensenonze de bioseguridad em la graduación de enfermería. Fueron analizados artículos de periódicos encontrados em la consulta de bases de datos LILACS, SCIELO, MEDLINE, BDENF, DEDALUS y PERIENF, identificando 26 artículos. Los resultados encontrados proporcionaron la formacíon y discusión de las categorías: "Bases ideológicas y teóricas", "Abordaje histórica de bioseguridad", "Riesgos ocupacionales y SIDA" y "Educación en bioseguridad en la formación". Se concluye que el número de artículos es pequeno, principalmente artículos que enfocan educación en bioseguridad, pero hubo una evolución de este contenido en los últimos ãnos.

Descriptores: Bioseguridad; Enseñanza; Graduación de enfermería.

Andrade AC, Sanna MC. Ensino de Biossegurança na Graduação de Enfermagem: uma revisão da literatura. Rev Bras Enferm 2007 set-out; 60(5): 569-72.
Submissão: $18 / 12 / 2006$ Aprovação: 23/06/2007

\section{INTRODUÇÃO}

A biossegurança é uma área de conhecimento relativamente nova, que impõe desafios não somente à equipe de saúde, mas também a empresas que investem em pesquisa. A biossegurança designa um campo de conhecimento e um conjunto de práticas e ações técnicas, com preocupações sociais e ambientais, destinados a conhecer e controlar os riscos que o trabalho pode oferecer ao ambiente e à vida $^{(1)}$.

É importante considerar que, com o advento daAIDS (Síndrome da Imunodeficiência Adquirida) em 
1981 e o primeiro relato de contágio acidental ocupacional em profissionais da saúde em 1984, surgiu maior preocupação com a biossegurança. Em 1987, foram instauradas as Precauções Universais como recomendações do CDC (Centers for Disease Control and Prevention), decorrente do desconhecimento sobre as medidas de biossegurança, que os profissionais deveriam tomar para prevenção da transmissão do HIV e do vírus da hepatite $\mathrm{B}^{(2)}$.

Frente a estes fatores, estudos mais profundos sobre os riscos ocupacionais iniciaram-se nesta mesma década, e portarias ministeriais disciplinaram o assunto. A Portaria 3.460/75 reconhece 0 enfermeiro como integrante da equipe de saúde ocupacional, e as Portarias 3.236/72 e 3.237/ 72 do Ministério do Trabalho, tornaram obrigatórios os serviços de saúde ocupacional nas empresas com mais de 100 profissionais ${ }^{(3)}$. Isto, no entanto, não é o suficiente para garantir a proteção dos trabalhadores. Segundo Londono et al ${ }^{(4)}$, com relativa freqüência, o pessoal que trabalha em uma instituição hospitalar entra na rotina em suas atividades a tal ponto que, sem se dar conta, vai aumentando sua confiança em relação a áreas, materiais ou pessoas que afluem ao hospital, e facilmente omitem procedimentos elementares como a lavagem das mãos e o uso de luvas, por exemplo. Além disso, com relativa freqüência, sob o pretexto de sua própria atividade, adentram áreas de alto risco, onde são emitidas elevadas doses de radiação, ou manuseiam soluções potencialmente tóxicas, sem uso dos equipamentos de proteção individual.

$\mathrm{Na}$ área da saúde pode-se observar um grande número de riscos ocupacionais, principalmente ao considerar-se que o hospital é o principal meio ambiente de trabalho dos profissionais que atuam nesta área ${ }^{(5)}$. Por isso, a adoção de normas de biossegurança no trabalho em saúde é condição fundamental para a segurança dos trabalhadores, qualquer que seja a área de atuação, pois o riscos estão sempre presentes. Entre estes riscos estão, por exemplo, a contaminação pelo HIV e hepatite B, que ainda pode ser mais alarmante quando nenhuma medida profilática é adotada(6).

No Brasil, as estatísticas de contaminação pelas hepatites virais, HIV e pela tuberculose entre trabalhadores da saúde após acidentes, são escassas. Quanto à AIDS, o Sistema de Vigilância Epidemiológica identifica como primeiro caso ocorrido em 1994, no município de São Paulo, um acidente ocupacional sofrido por um auxiliar de enfermagem, envolvendo agulha contaminada com sangue ${ }^{(7)}$. Estudos têm demonstrado que a contaminação de profissionais pelo HIV em acidentes pode ser evitada, se forem adotadas medidas de biossegurança .

O fator de prevenção mais importante é a atitude que cada indivíduo adota, graças a um processo educativo, pois, segundo Nichiata et al( ${ }^{(8)}, a$ própria equipe de enfermagem tem dificuldade em aderir às medidas de segurança que busquem a proteção ao risco de exposição, subestimando, muitas vezes, o próprio risco. Avaliando este fato, é importante nos perguntarmos como está sendo a formação destes profissionais e qual o treinamento recebido nas instituições de saúde, sobre a temática em estudo.

Segundo Costa et al(9) , a educação em biossegurança não foi inserida nas disposições legais de formação dos profissionais de enfermagem e, como conseqüência, apesar dos esforços pontuais para inclusão deste tema no nível superior, ainda existe um grande abismo entre a magnitude do problema e a formação e capacitação de recursos humanos para a prática profissional segura. Consequentemente existe uma deficiência na formação profissional do enfermeiro, no que tange à sua sensibilização para medidas em biossegurança na prática, e um dos responsáveis por esta deficiência pode ser a pouca atenção nos currículos dos cursos de graduação em enfermagem a este conteúdo, pois é comum o assunto ser abordado de forma sucinta, em programas e cargas horárias diferentes, resultando em conhecimento insuficiente( ${ }^{(6)}$.

Uma alternativa para verificar como os estudiosos localizaram o conteúdo de biossegurança na formação dos profissionais de enfermagem é a revisão da literatura sobre assunto. Nela se pode verificar o que já foi produzido e publicado sobre o tema; quem o tem estudado e quais proposições têm apresentado.

Com a possibilidade de trabalhar com este objeto de estudo no ensino de biossegurança, nossa perspectiva é investigar as variáveis: identificação do periódico, ano de publicação e temática abordada. Esta ação se justifica a necessidade de dar continuidade a uma pesquisa preliminar ${ }^{(10)}$ acerca deste conteúdo, investigando o quantitativo de publicações em biossegurança relacionado à formação do enfermeiro e acreditando na importância da educação em biossegurança na graduação para proporcionar condições seguras aos profissionais de enfermagem .

Para esta pesquisa é indispensável o conhecimento dos periódicos que falam sobre 0 assunto e também 0 ano destas publicações para posterior avaliação quanto à área temática, bem como, o conhecimento das temáticas abordado nestes periódicos levantados a partir de três descritores possibilitando a visualização da dimensão de interesse para esta temática pelos pesquisadores, além de possibilitar a formação de categorias para enriquecimento da discussão sobre o assunto, que neste estudo tem 0 objetivo de investigar o contexto em que se deram e conhecer o conteúdo das publicações acerca do ensino de biossegurança na graduação em enfermagem.

\section{METODOLOGIA}

Este trabalho é um estudo de revisão bibliográfica, em que se pretende analisar as publicações sobre biossegurança direcionadas para a formação de enfermeiros no Brasil.

Este levantamento foi realizado no período de abril a agosto de 2006, nas seguintes bases de dados: LILACS, SciELO, MEDLINE, BDENF, DEDALUS, da Universidade de São Paulo e PERIENF da EEUSP. Para tanto se empregou as palavras chaves: "biossegurança and enfermagem" e, em uma segunda busca, utilizou-se "biossegurança and educação". 0 critério para escolha das bases de dados refere-se ao fato de que estas concentram maior número de publicações na saúde, arbitradas e muitas vezes originadas de teses e dissertações. Por esse motivo dispensou-se as indicações de teses, livros textos, concentrando-se exclusivamente nos artigos de periódicos.

A partir desta estratégia, identificou-se 26 artigos. Em seguida, todos os resumos foram lidos e as publicações referentes exclusivamente a outras profissões, que não enfermeiros, foram excluídas; e selecionadas 17 obras. Após a leitura das obras capturadas foi feito um fichamento contendo as variáveis do estudo, bem como resumo do texto e comentários do pesquisador.

Com as 17 fichas preenchidas, procedeu-se ao agrupamento por similaridade e pertinência, do que surgiram as seguintes categorias temáticas: "Bases ideológicas e teóricas", "Abordagem histórica de biossegurança", "Riscos ocupacionais e AIDS" e "Educação em biossegurança na formação".

\section{RESULTADOS E DISCUSSÃO}

A distribuição das publicações apuradas pode ser apreciada na Tabela 1, notando-se que, apesar do amplo espectro percorrido na varredura bibliográfica que se iniciaram em 1944, as publicações aparecem em periódicos apenas a partir de 1995.

É possível visualizar também um crescente aumento de publicações na década seguinte, supondo-se que, após a normatização do assunto pelo Ministério do Trabalho, houve maior interesse por este tema e aumento de publicações na área de biossegurança em enfermagem ${ }^{(11)}$.

As publicações aparecem em maior número nas revistas de enfermagem vinculadas à academia e em menor nas revistas de outras áreas, evidenciando um maior interesse pela enfermagem por parte de docentes el ou alunos sobre o tema que pelos enfermeiros assistenciais ou gerenciais.

Apenas uma publicação aborda a história do surgimento do conceito de biossegurança $a^{(1)}$. 
Tabela 1. Distribuição dos trabalhos publicados sobre biossegurança/ enfermagem/formação, nos periódicos. Brasil, 2006.

\begin{tabular}{|c|c|c|c|c|c|c|}
\hline \multirow{2}{*}{ Periódicos / Ano } & \multicolumn{2}{|c|}{ 1995/1999 } & \multicolumn{2}{|c|}{$2000 / 2006$} & \multicolumn{2}{|c|}{ Total } \\
\hline & $\mathbf{N}$ & $\%$ & $\mathrm{n}$ & $\%$ & $\mathrm{n}$ & $\%$ \\
\hline Rev Esc Enferm USP & - & - & 3 & 17,6 & 3 & 17,6 \\
\hline Rev Bras Enferm & 1 & 5,9 & - & - & 1 & 5,9 \\
\hline Rev Gaúcha Enferm & 1 & 5,9 & 2 & 11,8 & 3 & 17,6 \\
\hline Acta Paul Enferm & - & - & 2 & 11,8 & 2 & 11,8 \\
\hline Rev Enferm UERJ & - & - & 1 & 5,9 & 1 & 5,9 \\
\hline Cad Saúde Pública & - & - & 3 & 17,6 & 3 & 17,6 \\
\hline Rev Soc Bras Méd Trop & 1 & 5,9 & - & - & 1 & 5,9 \\
\hline Rev Bras Educ Méd & - & - & 1 & 5,9 & 1 & 5,9 \\
\hline Rev Hist Cien Saúde Manguinhos & - & - & 1 & 5,9 & 1 & 5,9 \\
\hline Braz J Infect Dis & - & - & 1 & 5,9 & 1 & 5,9 \\
\hline Total & 3 & 17,6 & 14 & 82,4 & 17 & 100,0 \\
\hline
\end{tabular}

\subsection{Bases Ideológicas e Teóricas}

Na categoria "Bases ideológicas e teóricas", analisou-se os conceitos acerca de biossegurança presentes nos 17 artigos estudados. Este termo foi conceituado em cinco artigos (29,4\%), sendo dois publicados em 2000, dois em 2004 e um em 2005. Destes, quatro artigos ${ }^{(2,11,12,13)}$ trouxeram 0 conceito estabelecido pela Comissão de Biossegurança da Fundação Oswaldo Cruz de 1998, o qual é definido como "O conjunto de medidas voltadas para a prevenção, a minimização ou a eliminação de riscos inerentes ás atividades de pesquisa, produção, ensino, desenvolvimento tecnológico e prestação de serviços, que podem comprometer a saúde do homem, dos animais, do meio ambiente ou a qualidade dos trabalhos desenvolvidos".

Segundo Costa et al(22), a construção do conceito teve início na década de 70 na reunião de Asilomar na Califórnia, onde a comunidade científica iniciou a discussão sobre o termo biossegurança e, a partir daí, este termo vem sofrendo modificações ao longo dos anos. Inicialmente discutia-se o impacto da engenharia genética na sociedade e, posteriormente, na década de 80, incorporou a definição os chamados riscos periféricos: risco químico, físico, radioativo e ergonômico presentes em ambientes de trabalho na saúde.

Na década de 90, o conceito de biossegurança sofreu as mudanças mais significativas, pois foram inseridos na definição temas como ética em pesquisa, meio ambiente, animais e processos envolvendo tecnologia de DNA recombinante, chegando ao conceito presente nos artigos em discussão. Porém, ao analisar este conceito atual, conclui-se que há maior enfoque para o ambiente ocupacional, estendendo-se para a proteção ambiental.

\subsection{Abordagem Histórica de Biossegurança}

Nesta categoria foram classificados 4 artigos (23,5\%), dos quais três foram publicados em 2000 e um em 2004. Destes, um artigo enfoca a história da biossegurança no Brasil nas décadas de 70 e 80 e também é 0 único artigo que conta a história da biosseguança antes destas décadas, mas num enfoque bem particular. Segundo Almeida ${ }^{(1)}$, desde a instituição das escolas médicas e da ciência experimental, no século XIX, vêm sendo elaboradas noções sobre os benefícios e riscos inerentes à realização do trabalho científico, em especial nos ambientes laboratoriais.

Os outros três (3) artigos desta categoria relacionam o surgimento da biossegurança ao recrudescimento das doenças transmissíveis e, a partir daí, a ocorrência de uma revisão da prática profissional, uma vez que se tratava de doenças de alta mortalidade e morbidade. Nesta época, o CDC padronizou as precauções universais, que posteriormente foram denominadas de precauções padrão (PP), para os profissionais da saúde ${ }^{(2,8,14)}$.

$\mathrm{O}$ primeiro conceito se refere às precauções recomendadas contra sangue e fluidos corporais, incluindo principalmente a manipulação cuidadosa de instrumentos perfurantes e cortantes contaminados com materiais biológicos, pois estes materiais biológicos seriam capazes de transmitir 0 HIV. O segundo foi publicado em 1996, com o objetivo de controlar a infecção hospitalar, e que orienta a prevenção do contato com todos os fluidos corporais, secreções, excreções, pele não-íntegra e mucosas de todos os pacientes, e não somente os fluidos corporais que pudessem transmitir o $\mathrm{HIV}^{(23)}$.

Ao contextualizar estas definições, é possível confirmar a história contada através destes artigos, em que a biossegurança nasceu a partir do recrudescimento das doenças transmissíveis e com a preocupação inicial voltada aos profissionais da saúde, em especial aos profissionais de laboratórios e, consequentemente, com maior enfoque para o risco biológico, sendo este olhar perpetuado até os dias atuais.

\subsection{Riscos Ocupacionais e AIDS}

Esta categoria foi a que apresentou maior número de trabalhos, sendo classificados 12 artigos (70,5\%), um foi publicado em 1995, um outro em 1996, mais um em1999, quatro em 2000, três em 2004 e dois em 2005. Destes, todos os artigos citam o risco biológico com o motivador de medidas de biossegurança, devido ao risco da contaminação por HIV e hepatite B, pois a transmissão destes ocorre principalmente através da exposição ao material biológico, considerando que os profissionais de saúde são responsáveis pela assistência e manipulam este tipo de material, direta ou indiretamente $(14,15,16,17,18,19,20)$.

No Estado de São Paulo, segundo o Boletim Epidemiológico ${ }^{(24)}$ foram notificados 5.391 acidentes ocupacionais com material biológico entre janeiro/ 1999 a outubro/2003, das quais $60,6 \%$ referiam-se aos trabalhadores de enfermagem, seguidos dos funcionários da limpeza (8,9\%) e os médicos $(6,8 \%)$, seguidos ainda de outros profissionais. Nos Estados Unidos, a infecção pelo HIV ficou caracterizada como ocupacionalmente adquirida por 57 trabalhadores da Saúde ${ }^{(6,8,12)}$.

Os dados mostram a vulnerabilidade dos profissionais da enfermagem ao risco biológico e faz-se entender a preocupação destes pesquisadores, uma vez que a AIDS é doença em franca expansão, embora, para os profissionais de saúde, o risco de contaminação para o HIV seja estimado em 0,3\% após exposição percutânea ao sangue contaminado, enquanto temos outras infecções com risco de maior contaminação para estes profissionais, mas que não aparecem com tanto destaque nesta categoria. Segundo Farias et al ${ }^{(21)}$, a hepatite $B$ é a enfermidade infecciosa de maior incidência entre a equipe de enfermagem, ao lado da tuberculose pulmonar, outra enfermidade profissional dos trabalhadores de saúde.

Entre os artigos encontrados, dois ${ }^{(2,21)}$ expõem, além do risco biológico, os outros riscos presentes nos hospitais, visto que este é o principal meio ambiente de trabalho dos profissionais que atuam nesta área, e ainda salienta que, embora o hospital tenha a finalidade principal de recuperação da saúde, é também um ambiente repleto de riscos para a clientela e os profissionais.

\subsection{Educação em Biossegurança na Formação}

Nesta categoria foram enquadrados 8 artigos (47\%), um foi publicado em 1995, dois em 2000, três em 2004 e dois em 2005. Os artigos citam e atribuem importância à educação permanente para mudança de atitude e, consequentemente, de comportamento. Durante o Seminário Internacional de Biossegurança, realizado em agosto/2005, na cidade de São Paulo, discutiu-se a necessidade de criar uma cultura de biossegurança, salientandose que é indispensável que os profissionais relacionem o risco de acidentes às práticas cotidianas ${ }^{(22)}$. 
A forma de abordar e estudar biossegurança, nos últimos anos, ganhou novos contornos, pois segundo Gryschek et al ${ }^{(19)}$, houve mudanças acerca da definição de biossegurança nos últimos anos e, desta maneira, seria muito provável que profissionais, já com algum tempo de formação não tenham tido acesso a esses conhecimentos sobre biossegurança nem em seus currículos de formação, nem em programas de educação permanente.

É fundamental a conscientização e educação permanente dos profissionais proporcionando-Ihes condições para um trabalho seguro, bem como a oportunidade para reflexões, discussões críticas, atualização e adoção de medidas preventivas corretas ${ }^{(6,14,15,21)}$. Para tanto, é importante colocar a biossegurança em um cenário que permita aos demais profissionais que atuam com prevenção e controle de riscos ocupacionais, entenderem seus propósitos, suas contradições, e, principalmente, sua importância como instrumento de proteção da vida, em qualquer que seja o ambiente de trabalho.

A este propósito, dois artigos enfatizaram a importância da ausência deste conteúdo no ensino superior, principalmente nas carreiras ligadas à saúde, que até o momento não incorporaram a biossegurança em seus currículos. No Brasil, o assunto não está inserido nas diretrizes curriculares e nem na sua implementação nas instiutições de educação pública e privada de nível superior. Os artigos ainda reafirmam que biossegurança é uma ação educativa, devendo ser representada por um sistema de ensinoaprendizagem $^{(2,20)}$.

Assim como outros conteúdos discutidos na graduação em enfermagem, este é um tema importante, indispensável e atual para a formação deste profissional que estará atrelado as ações gerenciais de qualidade nos serviços de saúde.

\section{CONCLUSÃO}

A produção científica de enfermagem referente ao ensino de biossegurança na graduação em enfermagem surgiu a partir de 1995, com crescente aumento na década seguinte, evidenciando a importância que a enfermagem vem dando para o tema biossegurança. Os resultados obtidos apontam para a predominância de enfermeiros docentes como pesquisadores, vinculados à academia.

Chamou à atenção o fato dos artigos, em sua quase totalidade, abordarem com maior ênfase o risco biológico e aAIDS. Considerou-se que isto se dê, talvez, porque os profissionais de saúde são responsáveis pela assistência e estão constantemente em contato com este risco, embora outras doenças transmissíveis e outros riscos façam parte da vida profissional da enfermagem. É também marcante o destaque dado para a educação em biossegurança, que aparece em quase metade dos artigos, enfocando a importância da educação permanente com relação a este tema; além deste aspecto, dois artigos enfocam que biossegurança é um tema indispensável na formação do profissional enfermeiro, mas que até o momento parece não ter sido incorporado em seus currículos.

A partir deste levantamento esperamos contribuir para outras pesquisas, visto que, a partir deste conhecimento, o enfermeiro é responsável pela segurança ocupacional de toda a equipe de saúde de um determinado setor.

\section{REFERÊNCIAS}

1. Almeida ABS, Albuquerque MBM. Biossegurança: um enfoque histórico através da história oral. Hist Cienc Saúde Manguinhos 2000; 7(1): 171-83.

2. Souza M. Controle de riscos nos serviços de saúde. Acta Paul Enferm 2000; 13 (esp-pt I): 197-202.

3. Fernandes A. Os acidentes do trabalho - do sacrifício do trabalho à prevenção e à reparação. São Paulo (SP): LTR; 2003.

4. Londono M, Morera G. Administração hospitalar. Rio de Janeiro (RJ): Guanabara-koogan; 2003.

5. Souza M. Conhecimento e aplicação das precauções universais pelos elementos da equipe de enfermagem de um hospital governamental (dissertação de mestrado). São Paulo (SP); Departamento de Enfermagem, Universidade Federal de São Paulo; 1994.

6. Gir E, Takahashi RF, Oliveira MAC, Nichiata LYI, Ciosak SI. Biossegurança em DST/AIDS: condicionantes da adesão do trabalhador de enfermagem às precauções. Rev Esc Enferm USP 2004; 38(3): 245-53.

7. Center for Disease Control. Recommendations for prevention of HIV transmission in health care settings. MMWR 1988; 37: 5-6.

8. Nichiata LYI, Gir E, Takahashi RF, Ciosak SI. Evolução dos isolamentos em doenças transmissíveis: os saberes na prática contemporânea. Rev Esc Enferm USP 2004; 38(1): 61-70.

9. Costa MAF, Costa MFB. Educação e competência em biossegurança. Rev Bras Educ Med 2004; 28(1): 46-50.

10. Andrade AC, Sanna MC. O conteúdo de biossegurança na graduação em enfermagem - um estudo bibliométrico. In: Anais do $4^{0}$ Congresso Brasileiro Nursing; 2006 abr 27-8; São Paulo (SP), Brasil. São Paulo (SP): Ferreira e Bento; 2006.

11. Souza ACS, Tipple AFV, Gir E, Canini SRMS. Biossegurança: a produção científica em enfermagem. Rev Gaúcha Enferm 2000; 21 (1): 68-81.

12. Caixeta RB, Branco AB. Acidente de trabalho, com material biológico, em profissionais de saúde de hospitais públicos do Distrito Federal, Brasil, 2002/2003. Cad Saúde Pública 2005; 21(3): 737-46.

13. Garcia LP, Ramos BGZ. Gerenciamento de resíduos de serviços de saúde: uma questão de biossegurança. Cad Saúde Pública 2004; 20(3): 744-52.

14. Gir E, Silva AM, Costa FPP, Hayashida M. Alterações na prática profissional de enfermeiros de um hospital de ensino do interior paulista, em conseqüência ao surgimento do HIVIAIDS. Rev Gaúcha Enferm 2000; 21(2): 37-54.

15. Rodrigues $A B$, Magalhães MBB, Sales SMM. A questão do vírus da imunodeficiência humana e a autoproteção no trabalho. Rev Bras Enferm 1995; 48(3): 272-85.

16. Oliveira AD, Viegas CRS, Sabka E, Guerra M, Baltazar R. Conhecimentos sobre prevenção da SIDA entre profissionais e acadêmicos da área de saúde. Rev Gaúcha Enferm 1996; 17(2): 124-31.

17. Toledo Jr ACC, Ribeiro FA, Ferreira FGF, Ferraz RM, Greco DB. Conhecimento, atitudes e comportamentos frente ao risco ocupacional de exposição ao HIV entre estudantes de medicina da Faculdade de Medicina da Universidade Federal de Minas Gerais. Rev Soc Bras Med Trop 1999; 32(5): 509-15.

18. Souza M, Vianna LAC. Acidentes ocupacionais na equipe de enfermagem: um estudo em cinco hospitais do município de São Paulo. Acta Paul Enferm 2000; 13(esp-pt II): 58-61.

19. Gryschek ALFPL, Domingos JC, Figueiredo CRDL, Nichiata LYI, Osório LM. Necessidades de qualificação da equipe de enfermagem para a assistência aos clientes portadores do HIV e da AIDS. Rev Esc Enferm USP 2000; 34(3): 288-93.

20. Reis RK, Gir E, Canini SRMS. Accidents with biological material among undergraduate nursing students in a public Brazilian university. Braz J Infect Dis 2004; 8(1): 18-24.

21. Farias SNP, Zeitoune RCG. Riscos no trabalho de enfermagem em um Centro Municipal de Saúde. Rev Enferm UERJ 2005; 13: 167-74.

22. Agência Nacional de Vigilância Sanitária. Biossegurança. Rev Saúde Pública 2005: 39(6): 989-91.

23. Costa MAF, Costa MFB. Biossegurança: elo estratégico de SST. Rev CIPA 2002; 253.

24. Secretaria de Estado da Saúde de São Paulo. Programa Estadual de DST/AIDS. Boletim Epidemiológico AIDS/SP 2004; 1(2). 